\title{
As relações entre governos e as organizações sociais do campo no Mercosul
}

\section{Relations between governments and rural organizations in Mercosur}

\author{
Guilherme Augusto Guimarães Ferreira [D] \\ Universidade Anhembi Morumbi (UAM) \\ e PPGRI San Tiago Dantas (UNEAP, UNICAMP, PUC/SP) \\ E-mail: guilhermegferreira@outlook.com
}

Resumo: No início do século XXI, ocorreu um movimento de reforma institucional do Mercosul, marcado pela incorporação de diversos setores políticos e econômicos à institucionalidade do bloco, dentre os quais a agricultura familiar, no âmbito da Reunião Especializada sobre Agricultura Familiar do Mercosul (REAF). Assim sendo, este artigo realiza um estudo das relações entre governos e organizações sociais no âmbito de um processo de integração regional. Para tanto, apresenta uma descrição dos atores participantes da REAF e suas lógicas de participação, ao mesmo tempo em que analisa suas dinâmicas de interação. Quer-se contribuir para a reflexão sobre a atuação dos governos e das organizações sociais do campo no âmbito do Mercosul e dos processos de integração regional sul-americanos de forma geral.

Palavras-Chave: Mercosul; Agricultura Familiar; Organizações Sociais do Campo.

\begin{abstract}
At the beginning of the 21st century, there was na institutional review process in Mercosur, marked by the incorporation of several political and economic sectors to the institutionality of the sub-regional bloc, among which family farming in the scope of the Specialized Meeting on Family Farming (REAF). Therefore, this article conducts a study of the relations between governments and social organizations in a regional integration process. To do so, it presents a description of the actors in the REAF and their logics of participation, while analyzing their interaction dynamics. We want to contribute to the discussion about the acting of governments and rural organizations in the Mercosur and others South American regional integration processes.
\end{abstract}

Keywords: Mercosur; Family farming; Rural Organizations. 
FERREIRA, Guilherme Augusto Guimarães. As relações entre governos e as organizações sociais do campo no Mercosul

\section{Introdução}

Nos primeiros anos do século XXI, a América do Sul passou por um processo de mudanças políticas que provocou transformações na compreensão do papel que a região deveria ocupar e, sobremaneira, em como os processos de integração regional deveriam acontecer: a eleição de governos ligados a partidos de esquerda" - a chamada "onda rosa" (Pereira da Silva, 2010). Afinal, os governos eleitos convergiam em uma "atitude mais cautelosa em relação à liberalização unilateral" (Veiga \& Ríos, 2007) e no entendimento de que os processos de integração regional, além da sua tradicional dimensão econômica/comercial, deveriam assumir uma face social e de governança regional, ligada à ideia de que existia uma necessidade de impor limites aos avanços e efeitos da globalização e da liberalização econômica e, de forma articulada, promover os objetivos do desenvolvimento, sobretudo a redução da pobreza (Bizzozero, 2011).

Houve, desta forma, uma redescoberta da região como espaço de somatória de capacidades e forças para a construção de alternativas, por meio de práticas transfronteiriças formais e informais. Assim, o regionalismo que se desenha no início do século XXI é a manifestação de um novo consenso em firmar a integração regional sob novas formas de cooperação, em que os Estados, organizações sociais e lideranças regionais são os protagonistas (Riggirozzi \& Tussie, 2012).

No caso do Mercado Comum do Sul (Mercosul), essa nova perspectiva colocou a necessidade de repensar o papel dos atores sociais frente aos processos de integração regional. Criado em 1991, no marco do "regionalismo aberto" (Cepal, 1994), o Mercosul assumiu um caráter predominantemente comercial, cujo projeto fora "idealizado, gerido e implementado no seio do aparelho de Estado" (Vigevani, 1998, p.73), resultando em uma institucionalização reduzida, com graus mínimos de comprometimento entre os atores e concentração excessiva do poder decisório nas chancelarias e nos governos (Mariano, 2000).

\footnotetext{
${ }^{1}$ Entendemos o conceito de esquerda como uma ideologia política que pretende reduzir as desigualdades sociais, "tornar mais iguais os desiguais" (Bobbio, 2011, p.126). Está, assim, ligado à tradição que entende existir a necessidade de atuação do Estado para corrigir periodicamente a organização social, limitando o excesso de desigualdade (Bobbio, 2011).
}

Revista Brasileira de Políticas Públicas e Internacionais, v. 04, n. 03, dezembro/2019, pp. 196-218. 
FERREIRA, Guilherme Augusto Guimarães. As relações entre governos e as organizações sociais do campo no Mercosul

As supracitadas mudanças na conjuntura política sul-americana no início dos anos 2000, entretanto, geraram uma expectativa de que os processos de integração regional sulamericanos, e o Mercosul de modo particular, caminhariam em direção ao aprofundamento, sobretudo diante de uma aparente convergência entre os objetivos dos governos dos países que compõem o bloco. O resultado mais expressivo desse processo foi a ampliação institucional do bloco, que inseriu novas temáticas e atores em sua institucionalidade, dentre os quais as organizações sociais do campo, no âmbito da Reunião Especializada sobre Agricultura Familiar (REAF).

Assim, diante da necessidade de compreender as relações entre governos e organizações sociais no âmbito de um processo de integração regional, este artigo apresenta uma descrição dos atores participantes da REAF e suas lógicas de participação, ao mesmo tempo em que analisa suas dinâmicas de interação. Espera-se, assim, que mesmo diante da impossibilidade de abranger a totalidade das dimensões da REAF, possa-se contribuir para a reflexão sobre a atuação dos governos e das organizações sociais do campo no âmbito do Mercosul e dos processos de integração regional sul-americanos de forma geral.

\section{A Reunião Especializada sobre Agricultura Familiar do Mercosul (REAF)}

O debate sobre a política agrícola se fez presente desde os primeiros anos do Mercosul, haja vista o impacto das negociações comerciais regionais em um dos setores de grande importância nas economias dos países membros do bloco. Assim, nos primeiros anos do Mercosul, foram criadas duas instituições dedicadas à discussão de política agrícola dentro do Mercosul: o Subgrupo de Trabalho No 8: Política Agrícola (SGT8) e a Reunião de Ministros da Agricultura.

O SGT8 foi criado pela Tratado de Assunção ainda em 1991, com o objetivo de coordenar as políticas macroeconômicas e tratar, essencialmente, das questões ligadas às regras fitossanitárias e barreiras não tarifárias relativas aos produtos agrícolas. A Reunião de Ministros da Agricultura, por sua vez, foi criada em 1992, pela decisão do Conselho do Mercado Comum (CMC) $n^{\circ} 11 / 92$, com o intuito de trabalhar para a harmonização da política agrícola dos países do bloco (González, 2011).

Revista Brasileira de Políticas Públicas e Internacionais, v. 04, n. 03, dezembro/2019, pp. 196-218. 
FERREIRA, Guilherme Augusto Guimarães. As relações entre governos e as organizações sociais do campo no Mercosul

A agenda desses dois espaços, em convergência aos objetivos de liberalização comercial estabelecidos pelo bloco nos anos 1990, lastreados na ideia de promover a igualdade de condições para a produção agrícola mundial que se estava negociando no âmbito da Rodada Uruguai do então Acordo Geral de Tarifas e Comércio (GATT), atual Organização Mundial do Comércio (OMC), concentrou-se nas demandas dos fazendeiros do agronegócio, organizados junto à Federação de Associações Rurais do Mercosul (FARM) ${ }^{2}$, e dos empresários dos grandes complexos industriais agropecuários. De uma maneira geral, tratava-se da barganha por medidas que garantissem melhores condições de produção e o livre acesso aos mercados regionais para aqueles fazendeiros e/ou empresários que optassem por internacionalizar sua produção, de maneira a aproveitar as vantagens comparativas de cada país, ou mesmo por migrar para os países do bloco em que os custos de produção eram menores (Romano, 1996).

É preciso ressaltar que esses atores não encontraram dificuldades em impor sua agenda às instituições do Mercosul, ao contrário dos produtores da agricultura familiar. Afinal, já possuíam forte poder de influência junto aos Ministérios de Agricultura e aos governos nacionais, o que garantiu que seus interesses fossem contemplados na agenda da Reunião de Ministros da Agricultura e do SGT8 (Riella, 2002).

Nos mesmos anos 1990, a normativa do bloco indicava alguma preocupação com a produção agrícola familiar. Observa-se que na decisão do $\mathrm{CMC} \mathrm{n}{ }^{\circ}$ 01/92, o bloco expressou a sua preocupação em articular os pequenos e médios produtores rurais em torno do processo de integração. No entanto, devido, entre outras coisas, à compreensão prevalecente de que a agricultura familiar estava relacionada à pobreza e à miséria e que deveria ser alvo de políticas sociais e de assistência, foram poucos os avanços nas discussões em torno de políticas públicas nacionais e regionais de facilitação do comércio, de financiamento produtivo e de inserção dos produtores familiares no novo mercado regional que se formava.

\footnotetext{
${ }^{2}$ A Federação de Associações Rurais do MERCOSUL (FARM) congrega, atualmente, dez federações e confederações dos países do MERCOSUL ampliado: Confederação Rural Argentina (CRA), Sociedade Rural Argentina (SRA), Confederação Nacional de Agricultura da Bolívia (CONFREAGRO), Confederação de Pecuaristas da Bolívia (CONGABOL), Confederação da Agricultura e Pecuária do Brasil (CNA), Sociedade Rural Brasileira (SRB), Sociedade Nacional de Agricultura do Chile (SNA), Associação Rural do Paraguai (ARP), Associação Rural do Uruguai (ARU) e Federação Rural do Uruguai (FR).
}

Revista Brasileira de Políticas Públicas e Internacionais, v. 04, n. 03, dezembro/2019, pp. 196-218. 
Diante do domínio da agenda do SGT8, e das discussões sobre política agrícola no Mercosul de uma maneira geral, pelos interesses do agronegócio, as organizações sociais do campo de âmbito nacional e demais representantes da agricultura familiar se articularam e formaram, em 1994, a Coordenadora de Produtores Familiares do Mercosul (COPROFAM), com o objetivo de ser o contraponto aos representantes do agronegócio, defender os interesses da agricultura familiar junto aos governos do bloco e demandar políticas regionais diferenciadas para a agricultura familiar no âmbito do SGT8.

Frente ao Mercosul, a COPROFAM adotou uma postura de "apoio crítico" (Carvalho, 2011), caracterizada pela presença ativa e constante da organização nas atividades do SGT8, no sentido de conhecer o processo de integração, analisar suas consequências para a agricultura familiar e atuar de maneira reativa diante das ameaças à sobrevivência do setor, de forma a garantir que a integração econômica regional não afetasse negativamente os agricultores familiares.

Simultaneamente, ocorreu no Brasil um processo de consolidação do reconhecimento da agricultura articulada em torno da unidade familiar enquanto modelo de produção diferente e alternativo ao agronegócio, baseada em uma concepção multifuncional da produção agrícola, que não se esgota na simples oferta de produtos, mas se coloca como provedora de outros bens à sociedade, como a preservação dos recursos naturais e das paisagens, e como protagonista na dinamização dos espaços rurais (Wanderley, 2003).

Nesse sentido, Picolotto (2009) aponta que a atuação da COPROFAM junto ao Mercosul caminhou conjuntamente com o avanço do debate sobre a importância da produção familiar no Brasil, onde a Confederação Nacional dos Trabalhadores da Agricultura (CONTAG) assumiu a defesa de um projeto alternativo de desenvolvimento rural, ancorado na identidade da agricultura familiar. Consolidou-se, dessa forma, especialmente com a criação do Programa Nacional de Fortalecimento da Agricultura Familiar (PRONAF), em 1996, a categoria agricultor familiar, resultando na inserção dos temas próprios do setor na agenda do governo brasileiro, como alternativas para o comércio, formas de produção associadas, dimensões ambientais da produção rural, dentre outros.

Revista Brasileira de Políticas Públicas e Internacionais, v. 04, n. 03, dezembro/2019, pp. 196-218. 
FERREIRA, Guilherme Augusto Guimarães. As relações entre governos e as organizações sociais do campo no Mercosul

Contudo, esses dois processos, ainda que representem uma etapa importante para o fortalecimento da atuação das organizações sociais do campo no âmbito do Mercosul e para o amadurecimento do debate em torno da categoria agricultura familiar, são insuficientes para explicar, isoladamente, a criação da REAF, sobretudo diante de um cenário de poucos resultados alcançados pela atuação da COPROFAM no âmbito do SGT8. Parece-nos claro, assim, que as mudanças na conjuntura regional, nas estratégias de integração regional e no papel do Mercosul nas políticas externas dos membros do bloco, especialmente no caso do Brasil, se colocam como elementos relevantes para a compreensão do processo de criação da REAF.

O ano de 2003 foi um marco para o setor da agricultura familiar dentro do governo brasileiro. O Ministério do Desenvolvimento Agrário (MDA), sob o comando do então Ministro Miguel Rossetto, passou por processo de reestruturação da sua atuação internacional devido às novas diretrizes do governo que entendiam que, assim como o Ministério da Agricultura e Pecuária (MAPA), o MDA também estava vinculado ao comércio internacional de alimentos e, nesse sentido, era preciso que participasse das negociações comerciais regionais e internacionais. Ao mesmo tempo, com a criação da Coordenação-geral de Cooperação Humanitária e Combate à Fome (CGFOME) junto ao Ministério das Relações Exteriores (MRE), a soberania alimentar e o combate à fome foram inseridos na agenda da política externa brasileira.

Criou-se, dessa forma, o ambiente político e institucional que possibilitou que o combate à fome e a promoção da agricultura familiar passassem a exercer um papel mais relevante junto à política externa brasileira, sobretudo em razão da articulação entre o MDA e a CGFOME, que exerceu provisoriamente a assessoria internacional do ministério. Não se está afirmando, no entanto, que o agronegócio tenha sido negligenciado e/ou abandonado. O que reconhecemos é que houve uma abertura da política externa brasileira para a agricultura familiar, tradicionalmente excluída de tais espaços.

Ademais, é preciso destacar a atuação da divisão para a América Latina e Caribe do Fundo Internacional de Desenvolvimento Agrário (FIDA), que realizou campanhas e reuniões junto aos governos da região, colocando a necessidade de políticas específicas para a

Revista Brasileira de Políticas Públicas e Internacionais, v. 04, n. 03, dezembro/2019, pp. 196-218. 
FERREIRA, Guilherme Augusto Guimarães. As relações entre governos e as organizações sociais do campo no Mercosul

agricultura familiar e, por meio da Unidade de Coordenação Regional para o Mercosul do Fundo Internacional de Desenvolvimento Agrário (FIDA-MERCOSUR), buscava a consolidação de um espaço para a agricultura familiar junto ao bloco.

O embrião da proposta que culminou na criação da REAF originou-se no seminário organizado pela COPROFAM em dezembro de 2003, com apoio do FIDA-MERCOSUR, intitulado "As Assimetrias nas Políticas Econômicas e Agrícolas dentro do Mercosul". No final do evento foi produzido um documento chamado "Carta de Montevidéu" (COPROFAM, 2003) que, por intermédio do Chanceler brasileiro Celso Amorim, foi apresentado pela COPROFAM na XXV Reunião Ordinária do CMC.

Nessa carta, a COPROFAM pleiteou junto ao Mercosul o reconhecimento da agricultura familiar enquanto modelo de produção agrícola demandante de políticas públicas diferenciadas que, assim como aquelas dirigidas ao agronegócio, necessitavam ser harmonizadas em nível regional para que o setor pudesse se beneficiar das oportunidades geradas pela integração regional. Para tanto, propôs a criação de um espaço específico junto ao SGT8, com o objetivo de debater uma agenda de políticas públicas em nível regional para o setor.

A partir de então o governo brasileiro articulou a proposta de criação de uma reunião especializada sobre a agricultura familiar, apresentada durante a LIII Reunião Ordinária do Grupo Mercado Comum (GMC), em março de 2004. Na ocasião da LIV Reunião Ordinária do GMC, a proposta foi aprovada e transformada na resolução do GMC No 11/04, estabelecendo a criação da Reunião Especializada sobre Agricultura Familiar do Mercosul (REAF), com o objetivo de promover o fortalecimento das políticas públicas para a agricultura familiar no bloco, por meio da promoção e facilitação do comércio dos produtos oriundos do setor, o que implica em medidas que assegurem o aumento da capacidade produtiva e melhores condições de acesso aos mercados.

As atividades da REAF estão organizadas em quatro principais instituições: Seções Nacionais, Grupos Temáticos (GTs), Seção Regional e a Secretaria Técnica. As seções nacionais se reúnem uma vez a cada semestre, sempre antes da sessão regional, e são organizadas e presididas pelos respectivos coordenadores nacionais da REAF de cada país, designado pelos governos, que devem assegurar a participação dos representes das

Revista Brasileira de Políticas Públicas e Internacionais, v. 04, n. 03, dezembro/2019, pp. 196-218. 
FERREIRA, Guilherme Augusto Guimarães. As relações entre governos e as organizações sociais do campo no Mercosul

organizações sociais. É, desse modo, o espaço em que os governos e as organizações sociais do campo de cada país se reúnem para debater e construir consensos em torno da agenda e de propostas de políticas públicas a serem tratadas na seção regional.

A seção regional também é realizada a cada seis meses e é organizada e presidida pelo país que exerce a presidência pro tempore do Mercosul, com apoio da Secretaria Técnica. Seu objetivo principal é a elaboração da ata da REAF, composta por uma síntese dos trabalhos realizados pelos grupos temáticos ao longo do semestre, pelas propostas e projetos de políticas públicas e pelas recomendações ao GMC. A seção regional é o espaço em que os governos exercem o poder de decisão, deliberando por consenso sobre quais propostas e/ou recomendações serão enviadas para apreciação dos órgãos decisórios do Mercosul.

Os Grupos Temáticos (GTs) ou Comissões são os espaços em que ocorrem os debates sobre temas específicos da agenda e são elaborados os projetos de recomendações, resoluções e políticas públicas do ponto de vista técnico. As seções nacionais e regionais de cada GT antecedem, respectivamente, as seções nacional e regional da REAF. Atualmente, os trabalhos estão estruturados em torno de seis grandes temas: (i) Registros da Agricultura Familiar; (ii) Facilitação de Comércio; (iii) Mudanças Climáticas e Gestão de Riscos; (iv) Acesso à Terra; (v) Juventude Rural; e (vi) Igualdade de Gênero.

Adicionalmente a essas atividades, nos dias em que precedem a realização da reunião da Seção Regional, as organizações sociais e os coordenadores nacionais encontram-se separadamente. A seção plenária das organizações sociais é um espaço de participação restrito às organizações sociais do campo que participam da REAF, em que são debatidos os temas das agendas nacionais e da agenda regional, resultando em um documento com o posicionamento e as demandas desses atores, que é lido na seção plenária e, posteriormente, encaminhado para todos os membros da REAF.

A Reunião de Coordenadores Nacionais, por sua vez, reúne os representantes oficiais dos governos para fazer o balanço das Seções Nacionais, discutir sobre a metodologia dos debates e programar as próximas atividades das Seções Nacionais.

Por fim, tem-se a Secretaria Técnica da REAF, locada no Edifício Mercosul, em Montevidéu. A secretaria é responsável por assegurar o cumprimento do calendário das Revista Brasileira de Políticas Públicas e Internacionais, v. 04, n. 03, dezembro/2019, pp. 196-218. 
FERREIRA, Guilherme Augusto Guimarães. As relações entre governos e as organizações sociais do campo no Mercosul

reuniões, organizar a logística da seção regional, manter arquivo da documentação da REAF, prestar assessoramento técnico aos representantes da REAF junto aos outros órgãos do Mercosul, funcionar como o centro de comunicações para o intercâmbio de informações entre os membros, e demais funções que lhe sejam solicitadas.

Em termos de agenda, conforme Ferreira, Laisner e Lima (2015), os trabalhos desenvolvidos pela REAF evidenciam uma perspectiva que considera a multidimensionalidade do setor, representada pela diversidade dos temas abarcados pelos grupos temáticos que trabalham as mais variadas questões ligadas aos mecanismos de facilitação de comércio dos produtos da agricultura familiar, às políticas de acesso à terra, ao impacto das mudanças climáticas na produção agrícola familiar, e às preocupações em torno das mulheres e da juventude rural.

Dessa forma, a REAF procura atuar em uma lógica que desvincula as políticas públicas direcionadas à agricultura familiar da concepção que as colocam como uma reação compensatória para os efeitos indesejados da liberalização do comércio, transitando para o entendimento de que devem ser instrumentos de fomento à criação de um novo padrão produtivo e de desenvolvimento rural sustentável, ao mesmo tempo em que aponta para as possibilidades de se pensar a construção de um projeto de integração regional que seja, principalmente, um instrumento de promoção do desenvolvimento nos seus mais diferentes aspectos.

\section{Quem participa? Descrevendo governos e organizações sociais do campo}

O estudo de quaisquer instituições, sejam domésticas ou internacionais, perpassa uma primeira questão fundamental: Quem participa? Afinal, a análise de qualquer processo político demanda, antes de tudo, a caracterização dos atores envolvidos.

Quando pensamos em processos de integração regional, como é o caso do Mercosul, ainda que seu início seja dependente de uma decisão governamental, o seu desenvolvimento está vinculado, entre outras coisas, à mobilização de atores econômicos, políticos e/ou sociais em torno do processo. Aplicado no caso da REAF, esse entendimento resulta na determinação de dois principais atores a serem analisados, para além da burocracia da própria reunião

Revista Brasileira de Políticas Públicas e Internacionais, v. 04, n. 03, dezembro/2019, pp. 196-218. 
FERREIRA, Guilherme Augusto Guimarães. As relações entre governos e as organizações sociais do campo no Mercosul

especializada (a secretaria técnica estabelecida no edifício do Mercosul, em Montevidéu): os representantes governamentais e as organizações sociais do campo, apresentados a seguir.

\subsection{Os atores governamentais}

Os atores governamentais são os protagonistas no processo de integração do Mercosul, estando presentes em praticamente todas as institucionalidades do bloco. Afinal, a integração regional sul-americana foi pensada e construída, fundamentalmente, pelos executivos nacionais (Vigevani, 1998; Mariano, 2000).

Em termos de abrangência, a representação governamental junto à REAF, para além dos Estados-membros do Mercosul (Argentina, Brasil, Paraguai, Uruguai e Venezuela), conta com uma atuação sistemática de três dos cinco Estados-associados: a Bolívia, associada desde 1996 ao bloco, participa ativamente das atividades da REAF desde a primeira reunião, em 2004 (Mercosul, 2004); o Chile, também associado ao bloco desde 1996, iniciou sua participação na reunião especializada em 2005, na ocasião da IV REAF (Mercosur, 2005); por fim, o Equador, que se associou ao Mercosul em 2004, e tem acompanhado as reuniões desde a XVI REAF, em 2011 (Mercosur, 2011). Assim, a despeito da ausência de representação da Colômbia e do Peru, a reunião trabalha na perspectiva do chamado Mercosul Ampliado.

Os representantes governamentais, no âmbito da REAF, exercem duas diferentes funções: coordenador nacional e coordenador dos pontos focais. O coordenador nacional é o representante político do governo nacional, sendo o responsável por presidir a seção nacional, representar a delegação de seus países, manifestar o voto na seção plenária regional e, ainda, presidir e coordenar todo o trabalho da REAF durante a sua respectiva presidência pro tempore.

De uma forma geral, o cargo de coordenador nacional da REAF é ocupado pelo responsável pelas políticas públicas de agricultura familiar dentro dos ministérios de agricultura ou equivalentes. Os coordenadores dos pontos focais, mesmo que vinculados ao governo e respectivos ministérios, possuem um perfil mais técnico. São, geralmente, profissionais de carreira dentro dos governos e atuam diretamente nos grupos temáticos, acompanhando as discussões específicas de cada GT.

Revista Brasileira de Políticas Públicas e Internacionais, v. 04, n. 03, dezembro/2019, pp. 196-218. 
FERREIRA, Guilherme Augusto Guimarães. As relações entre governos e as organizações sociais do campo no Mercosul

Não existe, dessa forma, uma separação clara entre os representantes governamentais que atuam em nível regional e os que atuam em nível nacional. Na quase totalidade dos casos, tanto o coordenador nacional quanto os coordenadores dos pontos focais são profissionais que acumulam a participação junto à REAF com suas atribuições dentro das estruturas domésticas de governo a que pertencem.

\subsection{As organizações sociais do campo}

O objetivo de caracterizar as organizações sociais do campo participantes da REAF é um desafio, sobretudo devido à impossibilidade de apresentar as mais de cem organizações que, em alguma ocasião, estiveram presentes na reunião regional da REAF. A partir disso, diante dos diversos critérios possíveis, foram selecionadas as organizações sociais do campo que participaram de forma assídua e contínua das reuniões. Acreditamos que elas compõem uma amostra que permite traçar um diagnóstico fiel das características dos atores de maior impacto na REAF e, consequentemente, de maior relevância para o estudo realizado.

Das organizações sociais do campo da Argentina, destacam-se duas: a Federação Agrária Argentina (FAA) e a Federação de Organizações Nucleadas da Agricultura Familiar (FONAF). A FAA é uma entidade gremial de abrangência nacional que reúne cooperativas e associações de pequenos e médios produtores agrícolas. Fundada em 1912, a federação tem como principais bandeiras a democratização do acesso à terra e a defesa do desenvolvimento sustentável. É membro fundador da COPROFAM e participa da REAF desde a primeira reunião, em 2004.

A FONAF é uma instituição nacional que congrega aproximadamente 900 organizações de produtores agrícolas e de povos originários. Historicamente, sua atuação tem por estratégia a participação nos mais diversos organismos do governo argentino responsáveis pelas políticas públicas para a agricultura familiar, sendo a REAF, da qual participa desde 2007, entendida como mais um destes mecanismos de interlocução com o poder público argentino.

Podem-se separar as organizações sociais do campo brasileiras atuantes na REAF em três grupos: organizações de abrangência nacional e com pautas amplas, que contemplam os mais diferentes aspectos da atividade agrícola; organizações de abrangência nacional com

Revista Brasileira de Políticas Públicas e Internacionais, v. 04, n. 03, dezembro/2019, pp. 196-218. 
FERREIRA, Guilherme Augusto Guimarães. As relações entre governos e as organizações sociais do campo no Mercosul

pautas específicas; e organizações regionais com pautas específicas. No primeiro grupo, destacam-se a Confederação Nacional dos Trabalhadores na Agricultura (CONTAG) e a Federação Nacional dos Trabalhadores e Trabalhadoras na Agricultura Familiar (FETRAF); no segundo, a União Nacional das Cooperativas da Agricultura Familiar e Economia Solidária (UNICAFES); e no terceiro, o Movimento da Mulher Trabalhadora Rural do Nordeste (MMTR-NE), o Movimento Interestadual das Quebradeiras de Coco Babaçu (MIQCB) e o Conselho Nacional das Populações Extrativistas (CNS).

A CONTAG foi fundada em 1963, mas somente a partir de 1995, com sua filiação à Central Única dos Trabalhadores (CUT), foi que a agenda da agricultura familiar assumiu o protagonismo em sua atuação (Silva, 2012). A organização sindical é composta por 27 federações, que representam cerca de 4000 sindicatos e organizações de base de todo o país. A CONTAG é membro fundador da COPROFAM, e tem participado sistematicamente da REAF desde o início dos trabalhos.

A FETRAF surgiu em 2004, do rompimento de setores da CONTAG que defendiam uma representação mais específica da agricultura familiar, em oposição à ideia ampla de trabalhador rural vigente na confederação (Silva, 2012). É filiada à CUT e congrega algo em torno de 600 sindicatos rurais, com o objetivo principal de fortalecer a representação e as políticas públicas específicas para a agricultura familiar. Assim como a CONTAG, participa ativamente das atividades da REAF desde 2004, porém não está filiada à COPROFAM.

A UNICAFES é uma instituição nacional que congrega cerca de 1100 cooperativas de agricultores familiares. Fundada em 2005, tem por missão a promoção do cooperativismo enquanto instrumento de desenvolvimento local, atuando na defesa de políticas públicas de facilitação de comércio dos produtos originários da agricultura familiar e no fomento ao desenvolvimento de cadeias de complementação produtiva. Está presente nas reuniões da REAF desde a XVI edição, realiza em Minas, Uruguai, no ano de 2011.

O Movimento da Mulher Trabalhadora Rural do Nordeste (MMTR-NE) e o Movimento Interestadual das Quebradeiras de Coco Babaçu (MIQCB) são dois atores que possuem um perfil similar. O MNTR-NE, criado em 1986, é um movimento da região nordeste brasileira, filiado à Rede de Mulheres Rurais da América Latina e Caribe (REDE LAC), que tem por

Revista Brasileira de Políticas Públicas e Internacionais, v. 04, n. 03, dezembro/2019, pp. 196-218. 
FERREIRA, Guilherme Augusto Guimarães. As relações entre governos e as organizações sociais do campo no Mercosul

objetivo promover o reconhecimento da trabalhadora rural e o fortalecimento da perspectiva de gênero nas políticas públicas para a agricultura familiar. O MIQCB, por sua vez, é um movimento que reúne mulheres dos quatro estados brasileiros em que há maior ocorrência do coco babaçu: Maranhão, Tocantins, Pará e Piauí. Formalmente criado em 1995, atua na promoção do reconhecimento e do fortalecimento da mulher dentro do setor agroextrativista. São, portanto, duas organizações regionais com pautas específicas ligadas à questão da perspectiva de gênero na atividade agrícola. A primeira participa da REAF desde a terceira reunião, em 2005; a segunda, desde a sétima reunião, em 2007.

Por fim, temos o Conselho Nacional das Populações Extrativistas (CNS). O CNS é uma organização de abrangência regional, ao contrário do que seu nome possa sugerir, composta por extrativistas e pequenos produtores rurais dependentes dos recursos naturais da floresta amazônica. Vinculados às ideias de Chico Mendes, a pauta da organização está ligada à defesa de políticas públicas de fortalecimento do agroextrativismo, da democratização do acesso aos recursos naturais e da preservação ambiental. Atua junto à REAF desde 2009.

A delegação do Paraguai é composta por dois perfis de organizações sociais: gremial e cooperativistas. As organizações de caráter gremial de maior expressão são a União Agrícola Nacional (UAN) e a Organização Nacional Camponesa (ONAC). Ambas são organizações de abrangência nacional, filiadas à COPROFAM, e que tem como pauta principal a defesa de políticas públicas que assegurem a sustentabilidade produtiva da agricultura familiar. A UAN participa da REAF desde a sua criação, em 2004; a ONAC, desde a terceira reunião, no ano seguinte.

A Central Paraguaia de Cooperativas (CEPACOOP) e a Federação de Cooperativas de Produção (FECOPROD) são as principais representantes do cooperativismo paraguaio junto à REAF. A CEPACOOP reúne cerca de 500 produtores familiares de todo o Paraguai e tem por missão auxiliar e promover a venda nacional e a exportação dos produtos de origem familiar, sobretudo gêneros frutíferos. A FECOPROD, por sua vez, tem por finalidade o melhoramento das condições de produção agrícola, auxiliando os produtores familiares com assistência técnica e capacitação, tanto no que diz respeito ao processo de plantio e colheita, quanto na

Revista Brasileira de Políticas Públicas e Internacionais, v. 04, n. 03, dezembro/2019, pp. 196-218. 
FERREIRA, Guilherme Augusto Guimarães. As relações entre governos e as organizações sociais do campo no Mercosul

gestão comercial da produção. Ambas iniciaram sua participação nas reuniões da REAF em 2005, e desde então tem marcado presença constante.

A Associação de Mulheres Rurais do Uruguai (AMRU) e a Comissão Nacional de Fomento Rural (CNFR), ambos membros fundadores da COPROFAM, são as organizações sociais do campo uruguaias que tem acompanhado as atividades da REAF com maior frequência. A AMRU é uma organização nacional que reúne aproximadamente 200 mil mulheres, dentre produtoras familiares e assalariadas rurais. Dedica-se a promover a inserção comercial e produtiva das mulheres nos mais diversos setores da agricultura. Participa da REAF desde 2005.

A CNFR é uma entidade nacional de caráter gremial formada por 98 organizações de base, que representam cerca de 15 mil produtores familiares. Atua, basicamente, em duas frentes: defesa dos direitos trabalhistas dos trabalhadores do campo e capacitação técnica, visando melhorias na qualidade e na produtividade da atividade agrícola familiar. Está presente nas reuniões da REAF desde a primeira edição, em 2004.

A delegação boliviana conta, desde a criação da REAF, com a participação da Coordenadora de Integração de Organizações Econômicas Camponesas, Indígenas e de Povos Originários da Bolívia (CIOEC). Membro fundador da COPROFAM, a CIOEC é uma organização de abrangência nacional que congrega aproximadamente 2 mil organizações do campo em torno de uma pauta abrangente, que envolve questões relacionadas à soberania alimentar, gestão sustentável dos recursos naturais, sustentabilidade da produção agrícola familiar e economia solidária.

Os agricultores familiares do Chile são representados na REAF pelo Movimento Unitário Camponês e Etnias do Chile (MUCECH), membro da COPROFAM e presente na REAF desde 2004; e pela Confederação Nacional de Federação de Cooperativas e Associações Silvoagropecuárias do Chile (CAMPOCOOP), que participou pela primeira vez da REAF em 2005, na terceira reunião regional.

No que concerne às organizações sociais do campo do Equador e da Venezuela, elas participaram pela primeira vez na XVIII e na XX REAF, respectivamente. Entretanto, conforme consta nas listas de presença, a representação social desses países foi marcada por

Revista Brasileira de Políticas Públicas e Internacionais, v. 04, n. 03, dezembro/2019, pp. 196-218. 
FERREIRA, Guilherme Augusto Guimarães. As relações entre governos e as organizações sociais do campo no Mercosul

uma alta rotatividade das organizações sociais do campo presentes nas reuniões regionais. Dessa forma, por fins metodológicos, optou-se por registrar a presença de representação equatoriana e venezuelana sem, no entanto, detalhar essas organizações.

\section{Governos, Organizações Sociais do Campo e suas dinâmicas de interação}

Em geral, a dinâmica dos processos de integração regional é marcada pela interconexão entre o ambiente doméstico e o regional, em um contexto de relacionamento entre diferentes governos e grupos de interesses nacionais no âmbito de estruturas institucionais transnacionais. No caso da REAF, as próprias regras estabelecidas pelo regimento interno da reunião especializada reforçam essa lógica, na medida em que segmenta suas atividades entre as seções nacionais e as seções regionais (Mercosul, 2004). Portanto, analisar o comportamento dos atores governamentais e das organizações sociais do campo no âmbito da REAF implica em compreender seus objetivos e estratégias a partir de uma leitura que considera o nacional e o regional como esferas complementares, duas faces do mesmo debate em torno das políticas públicas específicas para a agricultura familiar.

A distinção entre atores governamentais e atores sociais exposta anteriormente, para além da origem da representação, retrata uma divisão entre atores com diferentes possibilidades de participação, determinadas pelas capacidades políticas e econômicas de cada ator e pelo formato institucional da reunião especializada (Hirst, 1996). No caso da REAF, essas condicionantes estão estabelecidas, ao menos em termos das regras institucionais, pelo disposto no artigo 26 do Regimento Interno do Grupo Mercado Comum:

Artigo 26 - Os subgrupos de trabalho e as comissões poderão desenvolver suas atividades em duas etapas, uma preparatória e outra decisória. Na etapa preparatória, os subgrupos de trabalho poderão solicitar a participação de representantes do setor privado. A etapa decisória estará reservada exclusivamente aos representantes de cada Estado Parte. (Mercosul, 1991, p.05, grifo nosso).

Ao reservar a etapa decisória à participação exclusiva dos atores governamentais, somado à determinação de que as decisões tenham que ser tomadas por consenso e com a

Revista Brasileira de Políticas Públicas e Internacionais, v. 04, n. 03, dezembro/2019, pp. 196-218. 
FERREIRA, Guilherme Augusto Guimarães. As relações entre governos e as organizações sociais do campo no Mercosul

presença de todos os Estados-partes, expressa no artigo $7^{\circ}$ do regimento interno da REAF (Mercosul, 2004), o Mercosul estabeleceu dois níveis de atores, em uma divisão baseada, fundamentalmente, entre aqueles que possuem e aqueles que não possuem direito ao voto.

O processo de barganha intergovernamental e a possibilidade da utilização do poder de veto por parte dos representantes governamentais, derivado do processo decisório por consenso, resultaram na atribuição de um papel central à seção plenária regional da REAF, momento em que ocorrem a elaboração e o escrutínio da ata final da reunião. Afinal, essa é a etapa em que os trabalhos desenvolvidos pela reunião especializada podem ser, de fato, transformados em projetos de resolução, de decisão e/ou de políticas públicas regionais a serem encaminhados para apreciação dos órgãos decisórios do Mercosul.

Contudo, mesmo que o ponto alto das atividades da REAF seja a seção plenária regional, não se pode desconsiderar a importância das discussões e debates realizados ao longo das seções nacionais e dos grupos temáticos. Afinal, a opção de um representante governamental por aprovar, vetar ou modificar uma proposta é, necessariamente, resultado de um cálculo político que considera, dentre outros fatores, as pressões dos diversos grupos nacionais interessados na matéria abordada. Nesse sentido, a atuação dos governos na REAF é marcada por uma postura de reação, na medida em que assumem a função de canalizar e responder às demandas das organizações sociais do campo.

O caso chileno ilustra essa percepção. As organizações sociais do Chile participam das atividades da REAF desde seu início, haja vista que o Movimento Unitário Camponês e Etnias do Chile (MUCECH) é membro fundador da COPROFAM e, portanto, esteve envolvido no processo de criação da reunião especializada. A primeira participação dos representantes do governo chileno, no entanto, ocorreu apenas em 2005, na ocasião da IV REAF. Adicionalmente, quando da criação do Fundo da Agricultura Familiar (FAF), o Chile, enquanto membro associado do Mercosul, ficou isento da obrigação de realizar qualquer tipo de doação ou aporte financeiro (Laisner \& Ferreira, 2014).

Contudo, a participação das organizações sociais chilenas desde 2004 tem sido financiada com os recursos da REAF, tanto pelas doações do Programa FIDA-MERCOSUR quanto, posteriormente, com os recursos disponibilizados pelo FAF. Diante disso, as

Revista Brasileira de Políticas Públicas e Internacionais, v. 04, n. 03, dezembro/2019, pp. 196-218. 
FERREIRA, Guilherme Augusto Guimarães. As relações entre governos e as organizações sociais do campo no Mercosul

organizações sociais do campo chilenas empreenderam uma campanha, por meio de declarações públicas durante as atividades da REAF, solicitando que o seu governo realizasse um aporte voluntário ao fundo, o que ocorreu em janeiro de 2016 (Mercosur, 2016).

Estes fatos indicam que, tanto o início da participação do governo chileno, quanto sua doação voluntária ao FAF, foram, se não determinadas, influenciadas diretamente pela pressão exercida pelas organizações sociais do campo. Em vista disso, a análise aponta para a importância do trabalho das organizações sociais enquanto atores de pressão sob seus respectivos governos, ao mesmo tempo em que confirma a adoção de um comportamento de reação às demandas dos atores sociais pelos representantes governamentais.

A atuação das organizações sociais do campo, por sua vez, tem por centralidade um objetivo comum, que permeia todas as atividades dessas organizações, tanto em nível doméstico quanto regional: o reconhecimento de que a agricultura familiar, que se diferencia do agronegócio tanto no que diz respeito à sua organização produtiva quanto no tocante ao objetivo e função da produção, é um setor produtivo que demanda políticas públicas específicas e diferenciadas (Niederle, 2016; Programa Regional del FIDA para el MERCOSUR \& Brasil, 2006).

Este objetivo macro é um fator indispensável para a articulação regional das organizações sociais do campo, cuja maior expressão foi a conformação da COPROFAM, que desempenhou um papel determinante no processo de criação da REAF. Ao mesmo tempo, a descrição das organizações sociais do campo realizada na seção anterior evidencia a existência de diferenças substanciais em termos de capacidades organizacionais, objetivos e históricos de atuação política entre esses atores, o que resulta em diferentes possibilidades, constrangimentos e limites para a participação em instituições regionais.

Um sintoma dessa heterogeneidade é o processo de ampliação do escopo identitário das organizações sociais do campo atuantes na REAF. No início das atividades da reunião, a ideia de "Agricultura Familiar" parecia ser suficiente para representar as organizações sociais do campo presentes nas atividades da reunião especializada que, em sua grande maioria, eram vinculadas à COPROFAM. No entanto, na medida em que outras organizações foram sendo

Revista Brasileira de Políticas Públicas e Internacionais, v. 04, n. 03, dezembro/2019, pp. 196-218. 
FERREIRA, Guilherme Augusto Guimarães. As relações entre governos e as organizações sociais do campo no Mercosul

incorporadas, houve uma pressão para que a REAF reconhecesse como atores legítimos os representantes dos diversos setores que, de alguma forma, estavam ligados à atividade agrícola.

Assim, o termo "Agricultura Familiar" deu lugar à "Agricultura Familiar, Campesina e Indígena", que é utilizado para simbolizar a inclusão dos assentados da reforma agrárias, dos extrativistas, dos trabalhadores rurais, dos povos originários e demais identidades nacionais vinculadas ao campo na REAF. Essa diversidade resultou, ainda, na conformação de diferentes estratégias e padrões de atuação e relacionamento entre os atores no âmbito da REAF, intimamente relacionados com as características de cada organização e os contextos nacionais em que estão inseridas.

Carvalho (2011), em estudo sobre a atuação das organizações sociais do campo do Brasil e do Paraguai na REAF, identificou que as organizações paraguaias, como a ONAC, a UAN e a CEPRACOOP apontam, como principal motivação para participação da REAF, a possibilidade de pressionar o governo paraguaio para que implemente políticas públicas domésticas de apoio à agricultura familiar. Já sobre as organizações brasileiras de abrangência nacional, especialmente a CONTAG e a FETRAF, a autora afirma que, ainda que a ideia de solidariedade com as organizações sociais do campo dos demais países do cone sul esteja presente, suas estratégias de participação são marcadas pelo entendimento de que a REAF representa uma oportunidade para que essas organizações se coloquem como atores internacionais relevantes e ampliem seu poder frente a outros espaços de negociação internacional.

A partir disso, desenham-se dois modelos de atuação: um primeiro, ligado à concepção de que a REAF deve ser um espaço para que as organizações sociais do campo possam encaminhar demandas nacionais junto aos seus respectivos governos; e um segundo, que tem a REAF como plataforma de internacionalização da atuação política das organizações sociais do campo.

Pode-se identificar que, em geral, as organizações sociais do campo que possuem objetivos específicos, ligados a soluções nacionais mais imediatas, participam das atividades da REAF motivadas pela possibilidade de contato e influência sobre o governo de seu respectivo país de origem, para pressioná-lo no sentido de criar e/ou alterar políticas públicas nacionais

Revista Brasileira de Políticas Públicas e Internacionais, v. 04, n. 03, dezembro/2019, pp. 196-218. 
FERREIRA, Guilherme Augusto Guimarães. As relações entre governos e as organizações sociais do campo no Mercosul

para o setor. São organizações que, geralmente, não possuem tradição de participação em nível doméstico e internacional, localizadas em países que, muitas vezes, nem mesmo dispõem de estruturas governamentais domésticas que possibilitem o contato entre essas organizações e seus respectivos governos.

Por outro lado, tem-se organizações sociais do campo que são estruturadas em torno de pautas abrangentes, dotadas de recursos humanos e financeiros para acompanhar uma instância política regional que trabalha em uma perspectiva de longo prazo, como a REAF, e que possuem um histórico de atuação doméstica e internacional consolidado. Essas organizações sociais atuam na REAF com o objetivo de fortalecerem-se em relação aos seus respectivos governos nacionais e, concomitantemente, ampliar seu poder de influência nas disputas políticas. Desse modo, adotam uma estratégia de, a partir da REAF, regionalizar e/ou mundializar a agenda e os debates já realizados por elas, de forma a sedimentar e expandir sua influência em nível doméstico, regional e mundial.

A interação entre as diferentes estratégias e objetivos das diversas organizações sociais do campo e dos diferentes governos, contudo, não impedem que consensos sejam construídos. Nos discursos analisados e nos documentos produzidos pelos governos, pelas organizações sociais do campo e pela própria REAF, existe uma compreensão praticamente unânime de que a reunião especializada deve funcionar, antes de tudo, como uma plataforma de diálogo político, cuja contribuição mais relevante é possibilitar o contato e o intercâmbio de informações e experiências entre os diversos atores envolvidos. Conjuntamente, a seção nacional da REAF consolidou-se como um espaço que, para além de debater a agenda proposta pela REAF, passou a ser utilizada para tratar das questões domésticas.

\section{Considerações Finais}

Ao longo deste texto, buscou-se apresentar uma descrição dos atores participantes da REAF e suas lógicas de participação, ao mesmo tempo em que foi apresentada uma análise de suas dinâmicas de interação, com o objetivo de contribuir para a reflexão sobre a atuação dos governos e das organizações sociais do campo no âmbito do Mercosul e dos processos de integração regional sul-americanos de forma geral.

Revista Brasileira de Políticas Públicas e Internacionais, v. 04, n. 03, dezembro/2019, pp. 196-218. 
FERREIRA, Guilherme Augusto Guimarães. As relações entre governos e as organizações sociais do campo no Mercosul

Em síntese, argumentou-se que a convergência de interesses dos governos e das organizações sociais do campo, em uma conjuntura regional fértil para que as iniciativas do chamado Mercosul Social florescessem, resultou na construção de um espaço de discussão específico sobre a agricultura familiar. Nesse processo, a mobilização e atuação ativa das organizações sociais do campo, representados pela COPROFAM, foi crucial para incluir a temática da agricultura familiar e os agricultores familiares em uma institucionalidade que, mesmo subordinada ao GMC, aponta para a construção de um Mercosul em que os atores e temáticas que foram excluídos do modelo de integração dos anos 1990 estariam cada vez mais presentes.

No que se refere à participação das organizações sociais do campo, demonstramos que a REAF conseguiu assegurar a ampla presença de diversas organizações sociais do campo em suas atividades, tanto nacionais quanto regionais. Ao mesmo tempo, diante da heterogeneidade dos atores envolvidos, foi possível caracterizar dois diferentes modelos de atuação das organizações sociais do campo no âmbito da REAF.

Afirmamos, assim, que para as organizações sociais do campo que possuem objetivos específicos, ligados a soluções nacionais mais imediatas, prevalece a concepção de que a REAF deve operar como espaço de contato com os governos nacionais. Logo, a lógica de atuação é de utilização dos espaços regionais para demandar e influenciar políticas públicas domésticas.

Já para as organizações sociais do campo estruturadas em torno de pautas abrangentes, a REAF assume o papel de ser uma plataforma de internacionalização da atuação política. Isto é, os espaços de ação regionais operam como um trampolim para projetar sua influência em nível doméstico e em outras instâncias internacionais, tais como aquelas vinculadas à Organização das Nações Unidas para Alimentação e Agricultura (FAO) e à Organização das Nações Unidas (ONU) de uma forma geral.

Portanto, as dinâmicas de participação das organizações sociais do campo no Mercosul materializam uma visão parcial e essencialmente nacional do processo de integração. Dessa forma, a articulação em âmbito regional é utilizada para fortalecer os posicionamentos e demandas de cada organização social do campo em negociações nacionais e/ou internacionais

Revista Brasileira de Políticas Públicas e Internacionais, v. 04, n. 03, dezembro/2019, pp. 196-218. 
FERREIRA, Guilherme Augusto Guimarães. As relações entre governos e as organizações sociais do campo no Mercosul

em que estejam envolvidas, em uma lógica em que os interesses e demandas particulares se sobrepõem a um possível interesse regional do setor.

\section{Referências}

Bizzozero, L. (2011). América Latina a inicios de la segunda década del siglo XXI: entre el regionalismo estratégico y la regionalización fragmentada. Revista Brasileira de Política Internacional, 54(01), 29-43.

Bobbio, N. (2011). Direita e Esquerda: razões e significados de uma distinção política. São Paulo: Editora UNESP.

Carvalho, P. (2011). Ação Coletiva Transnacional e o MERCOSUL: organizações da sociedade civil do Brasil e do Paraguai na construção da Reunião Especializada sobre Agricultura Familiar (REAF) (Dissertação de Mestrado).Universidade de Brasília, Brasília, DF, Brasil.

Cepal (1994). El regionalismo abierto em America Latina y el Caribe: la integración económica al servicio de la transformación productiva com equidad. Santiago de Chile: CEPAL.

COPROFAM (2003). Carta de Montevideo: Propuesta de la Coprofam al Consejo del MERCOSUR. Recuperado de http://www.fidamercosur.org/site/images/BIBLIOTECA/FaseI_1999_2003/CARTA\%20DE\%2 0MONTEVIDEO.pdf

Ferreira, G. A. G., Laisner, R., \& Lima, V. (2015). Regionalismo e Desenvolvimento: A Reunião Especializada sobre Agricultura Familiar do Mercosul (REAF). Revista Videre, 07(01), 91-100.

González, L. (2011). La Reunión Especializada sobre Agricultura Familiar del MERCOSUR. Creación y avances de un novedoso espacio en la agenda de la integración regional. Densidades, 8(01), 9-78.

Hirst, M. (1996). A Dimensão Política do MERCOSUL: atores, politização e ideologia. In Zylberstajn, H. et al. (Ed.), Processo de Integração Regional e Sociedade: o sindicalismo na Argentina, Brasil, México e Venezuela. Rio de Janeiro: Paz e Terra.

Laisner, R., \& Ferreira, G. A. G. (2014). Políticas públicas de desenvolvimento no MERCOSUL: A reunião especializada sobre agricultura familiar e o Fundo da Agricultura Familiar. Bahia Análise \& Dados, v.24, n.3.

Revista Brasileira de Políticas Públicas e Internacionais, v. 04, n. 03, dezembro/2019, pp. 196-218. 
FERREIRA, Guilherme Augusto Guimarães. As relações entre governos e as organizações sociais do campo no Mercosul

Mariano, M. (2000). A estrutura institucional do Mercosul. São Paulo: Aduaneiras.

Mercosul (1991). Decisão do Conselho do Mercado Comum $N^{\circ}$ 04/91: Regimento Interno do Grupo Mercado Comum. Recuperado de http://www.oconsumidor.gov.br/barreirastecnicas/pdf/acordos/CMCDec1991_4.pdf

Mercosul (2004). Reunião Especializada sobre Agricultura Familiar, 01;02.; Foz do Iguaçu, 2004. Ata no 01/04. Anexo IV. Foz do Iguaçu.

Mercosur (2005). Reunión Especializada de la Agricultura Familiar, 04.; Montevideo, 2005. Acta $n^{\circ} 02 / 05$. Montevideo.

Mercosur (2011). Reunión Especializada de la Agricultura Familiar, 16.; Minas, 2011. Acta $n^{o}$ 02/11. Minas.

Mercosur (2016). Reunión Especializada de la Agricultura Familiar, 25.; Montevideo, 2016. Acta $n^{\circ}$ 01/16. Montevideo.

Niederle, P (2016). REAF MERCOSUR: una década de coprodución de politicas públicas entre el Estado y la sociedad civil. Porto Alegre: FAO.

Pereira da Silva, F. (2010). Até onde vai a "onda rosa"? Análise de Conjuntura OPSA, Rio de Janeiro, 02(01), 01-20.

Picolotto, E. (2009). A emergência dos "agricultores familiares" como sujeitos de direitos na trajetória do sindicalismo rural brasileiro. Mundo Agrário, 9(18), 01-39.

Programa Regional del FIDA para el Mercosur \& Brasil (2006). Ministério do Desenvolvimento Agrário. Primeiro Ciclo REAF. Porto Alegre: FIDA-MERCOSUR; MDA.

Ramos, A. (2016, abril). Taller Repensando la REAF [arquivo de vídeo]. Recuperado em 15/01/2019, de https://www.youtube.com/watch?v=PHALSVsNqc0.

Riella, A. (2002). Las Organizaciones Rurales y el proceso de integración regional. Revista de Ciencias Sociales, 15(20), n.20, 75-86.

Riggirozzi, P., \& Tussie, D. (2012). (Ed.). The rise of post-hegemonic regionalismo: the case of Latin America. New York: Springer.

Romano, J. (1996). Atores e Processos sociais agrários no MERCOSUL. Estudos Sociedade e Agricultura, 6(01), 91-113.

Revista Brasileira de Políticas Públicas e Internacionais, v. 04, n. 03, dezembro/2019, pp. 196-218. 
FERREIRA, Guilherme Augusto Guimarães. As relações entre governos e as organizações sociais do campo no Mercosul

Silva, C. A. (2012). Consolidação de uma agenda para o desenvolvimento rural sustentável e solidário: documento final contendo análise e avaliação da participação social na formulação e construção de propostas sobre as temáticas da agricultura familiar e desenvolvimento rural nos processos de integração do MERCOSUL. Brasília: Instituto Interamericano de Cooperação para a Agricultura.

Veiga, P., \& Ríos, S. (2007). O regionalismo pós-liberal na América do Sul: origens, iniciativas e dilemas. CEPAL - Série Comércio Internacional, 82(01), 05-48.

Vigevani, T. (1998). MERCOSUL: impactos para trabalhadores e sindicatos. São Paulo: LTr.

Wanderley, M. (2003). Prefácio. In Carneiro, M., \& Maluf, R. (Ed). Para além da produção: Multifuncionalidade e Agricultura Familiar. Rio de Janeiro: MAUAD.

Revista Brasileira de Políticas Públicas e Internacionais, v. 04, n. 03, dezembro/2019, pp. 196-218. 